\title{
Does Teacher Encouragement Influence Students' Educational Progress? A Propensity-Score Matching Analysis
}

\author{
Benjamin Alcott $^{1}$ (D)
}

Received: 15 October 2015/Published online: 13 January 2017

(C) The Author(s) 2017. This article is published with open access at Springerlink.com

\begin{abstract}
Theory suggests that teacher encouragement can aid students' educational progress, but there are not yet quantitative inferential studies that assess its longer-term impact. With data from the Longitudinal Study of Young People in England (LSYPE), I use propensity-score matching to investigate whether encouragement influences the likelihood of students enrolling in (1) advanced high school (A-level) courses and (2) a university degree course. Model estimates suggest that encouragement does have a significant positive impact on both outcomes. In addition, I investigate whether encouragement effects vary according to parental education and the given student's prior academic achievement; it appears that the impact is greatest for those students in the middle third of academic achievement as well as those with lower levels of parental education. These findings have important policy implications, especially as it seems that teacher encouragement has the greatest influence on those students most likely to be on the margin for university attendance.
\end{abstract}

Keywords Teacher encouragement - College access · Post-compulsory education · Propensity-score matching

\section{Introduction}

England possesses one of the world's elite university ${ }^{1}$ systems, with its prestigious institutions among the most widely recognized and highly ranked (Shanghai Ranking Consultancy 2014; Times Higher Education 2015; U.S. News and World Reports 2015). But

1 Throughout this manuscript, the term "university" is used rather than the term "college." This is to avoid confusion for those more familiar with the UK context. Generally, UK universities are equivalent to fouryear colleges in the US, whereas UK colleges tend to offer vocational courses aimed at students aged 16-19.

Benjamin Alcott

bma27@cam.ac.uk

1 Faculty of Education, University of Cambridge, 184 Hills Road, Cambridge CB2 8PQ, UK 
this should not mask the fact that participation in higher education, particularly at the most prestigious institutions, is highly stratified (Archer et al. 2003; Ball 2008; Reay 2005). Between the 1960s and 1990s, the link between parental income and university enrollment grew (Blanden and Machin 2004; Galindo-Rueda et al. 2004; Glennerster 2001; Machin and Vignoles 2004). Research indicates that this class gap has not eroded in more recent years: although it may be true that more students of low socioeconomic status are staying in formal education beyond the tenth $\operatorname{grade}^{2}$ (the point at which school attendance in England ceases to be compulsory), this closing of the socioeconomic enrollment gap has not carried over to the high school/university nexus (Chowdry et al. 2008; Jackson 2011).

Socioeconomic disparities in enrollment closely correspond to achievement disparities at the high school level. Among students with similar high school qualifications, socioeconomic disparities in university attendance are small (Vignoles 2013). Consequently, Britain's incumbent government has focused on schoolteachers as key to redressing access inequalities (Reay 2013), but in a somewhat narrow manner: teachers are judged primarily by their ability to teach students the core content necessary for them to pass national examinations (Stevenson and Wood 2014).

The aim of this study is to broaden policy debates on the role of teachers in influencing university access in England. Rather than limiting their role to teaching course material, I consider teachers' contribution in encouraging students. In order to do this, I use propensity-score matching analysis to estimate the impact of teacher encouragement (as reported by students at age 15-16) on students' persistence in education beyond the compulsory years of high school: first to non-compulsory, advanced high-school classes $\left(\right.$ A-levels $\left.{ }^{3}\right)$, then to university.

While encouragement has been discussed in past educational research, this has typically been in relation to sociology and educational psychology rather than policy development (for example, McHarg et al. 2007; Moogan 2011; Reay et al. 2001). Two dimensions of this study offer a better fit to the needs of policy research. First, I analyze a dataset that enables large-scale, quantitative inferential analysis. In contrast, prior studies of encouragement of school students often undertake constructivist analytical approaches on small student samples, but, while important, these approaches tend to encounter concerns about the generalizability of their findings to the national scale. Second, the longitudinal nature of this analysis enables inferential claims about sustained effects. Whereas past studies of teacher encouragement commonly examine effects within the same academic year, I connect reported teacher encouragement to student outcomes that occur years later.

The primary contributions of this study are to broaden our understanding of which students tend to receive teacher encouragement, whether encouragement influences students' future educational trajectories, and whether any influence differs according to student background. The findings show that students with higher prior achievement and more educated parents are the most likely to report encouragement; in other words, teachers tend to encourage students from groups already well represented in postsecondary education. Even accounting for these apparent biases though, teacher encouragement appears to have a positive impact on students' educational progress, both to A-levels and to university. This

\footnotetext{
2 Here, "tenth grade" follows US terminology. In England, this school grade is known as Year 11.

3 "A-levels" are generally considered the most academic courses available over the final two years of high school in England. Although they are not formally a pre-requisite for university study, they tend to be treated as such. Since school ceases to be compulsory for the final two years of high school, the other main alternatives students have to A-levels are more vocational courses, apprenticeships, and employment. For the cohort considered in this study, $60 \%$ enrolled in A-levels.
} 
finding substantiates the claim that students' educational progress depends, at least partially, on the social cues they receive in the formal school structure. Perhaps more importantly though, this positive impact is greatest for students with lower socioeconomic status and for students with middling levels of prior attainment. Teacher encouragement has, it seems, particularly large benefits for students who are from underrepresented backgrounds and on the margin of university attendance.

\section{Theory and Literature}

The theory of habitus provides this study's conceptual underpinning. In line with much prior research on educational access in England, I focus on habitus as conceptualized primarily by Pierre Bourdieu. While Bourdieu emphasized that humans operate within social structures, he eschewed deterministic theories in favor of an approach that would acknowledge the existence of human agency, albeit contingent on social position (Bourdieu 1986; Bourdieu and Wacquant 1992; Ovenden 2000). Habitus provides a conceptual tool that balances these factors. It is the attitudes and tendencies that one develops as a result of interactions with others, as well as one's ensuing actions (Bourdieu 1998; Nash 2005; Reay 2004). Cultivated over time, an individual's habitus forms a range of dispositions and behaviors indicating what she considers to be appropriate, desirable and possible. While an individual's decision-making is not fixed across the lifespan, it is bounded at a given time according to prior opportunities and constraints.

While acknowledging that the aspects of identity that shape an individual's habitus are numerous, Bourdieu and co-authors' (Bourdieu 1998, 2005; Bourdieu and Passeron 1977, Bourdieu and Wacquant 1992) work on educational structures emphasized social class. ${ }^{4}$ Simply put, schools reward middle- and upper-class norms. Consequently, working-class students face a greater onus to "engage in rational computation in order to reach the goals that best suit their interests" (Bourdieu 1990, p. 108), and are vulnerable to stigmatization should they behave in line with their own "vulgar" habituses (Bourdieu and Passeron 1979).

Exponents of habitus in the English context echo Bourdieu's claims about the importance of social class in formal education. A common line of argument is that school environments instill in students a sense that the most feasible and desirable post-school options are those that mirror the students' own socioeconomic backgrounds (Thrupp 1999). In Ball et al.'s (2002a) study, a student at one private, fee-paying school tells interviewers,

I thought about would I go to Cambridge or not, because quite a lot of people, you know always think-am I going to Cambridge or not? I don't know why, that just seems to be the question a lot of people ask themselves about higher education. (p. 58)

In contrast, one working-class respondent recalls from a visit to Cambridge, "it was like a proper castle, and I was thinking-where's the moat, where's the armor? Save me from

\footnotetext{
4 Social class remains a contentious topic in England (Foster et al. 1996). Precedents in classifying social class include parental occupation type, parental income, parental education, speech, and clothing, while other researchers argue that any classification is counterproductive, instead preferring undefined, subjective assessments (Archer et al. 2003; Savage 2000). In spite of this, researchers of university access in England have rarely directly disputed one another's definitions, or lack thereof, of social class. Officially, the UK Government defines "working class" adults as those engaged in routine or manual occupations (Rose et al. 2005, p. 38).
} 
this" (Ball et al. 2002a, p. 68). This is corroborated by Archer and Hutchings (2000), who found that young working-class adults from ethnically diverse communities in London held clearly defined identities according to speech and dress that separated them from the tastes of young people who would go to university. Consequently, many working-class students do not aspire to university because they do not see it as a place for them (Archer et al. 2003; Reay 2006); in contrast, middle- and upper-class students tend to come from families with a history of higher education participation, and so the decision to apply to and attend a university is relatively smooth (Ball et al. 2002b).

Scholars who have applied Bourdieu's concepts to the UK education system have tended to theorize, much as Bourdieu did himself, that teachers are a complicit, rather than a resistant, component of an education system that perpetuates socioeconomic disparities (see, for example, Bourdieu 1990; Bourdieu and Passeron 1990; Redmond 2006). In the latter years of school, teachers may give differential guidance to students according to social class (Preston 2003; Reay 1998). Qualitative fieldwork indicates that teachers tend to under-appreciate the achievements of working-class students (Reay 2005; Redmond 2006), typically placing them in lower ability streams and less academically challenging subjects. Researchers in this field have attributed this tendency among teachers to conflate middleand upper-class behaviors with cleverness and working-class behaviors with stupidity (Ball 2003; Reay 2005). Such designations are likely to have a lasting impact on students' academic confidence and important repercussions for their university applications (Boaler 1997; Steedman 1988; Thomas et al. 2012).

Whether intentional or not, such discrimination by teachers is exacerbated by households, as distinctive class strategies are apparent in families' reactions to such judgments (Ball 2003): since the formal school system reflects the norms of middle- and upper-class behaviors, working-class families are more dependent on, and susceptible to, teachers' opinions of their children's achievement and behavior (Gunn 2005; Lareau 1997). In part, this is because parents of higher social classes are often more comfortable engaging with schoolteachers, applying pressure to ensure favorable outcomes for their children (Cochrane 2007, 2011; Giddens 1991; Reay 1995). For example, Pugsley (1998) contrasts middle- and upper-class parents who are willing to demand that teachers provide advice on A-level subject choices with working-class parents who are reluctant to initiate any contact, as exemplified by one interviewee who notes, "you don't like to interfere really. You can't, can you?" (p. 79).

However, there is also a competing body of research on conditions in the UK that works from Bourdieu's theorizations but instead depicts teachers as "agents of transformation rather than reproduction" (Mills 2008, p. 80). Such work has argued that many teachers consciously resist pressures to perpetuate social stratification (Crossley 2001), and that these resistant behaviors may be intrinsic to the formation of a student's habitus (Sayer 2005). Oliver and Kettley (2010) argue that teachers' promotion of university applications is key to whether students from underrepresented backgrounds apply, and, across the public schools ${ }^{5}$ that they surveyed, they find contrasting instances of proactive encouragement and reticence that were not defined by students' socioeconomic status.

Student-teacher relationships are key to forming a student's attitude towards formal education (Hollingworth and Archer 2009), and Reay et al. (2009) emphasize the importance to students' plans of relations with individual teachers rather than institutional culture. While also working from Bourdieu's conceptual foundations, this literature provides

5 I.e., government funded schools that are free of charge to pupils. In the UK these would typically be referred to as "state schools." 
competing qualitative evidence of the potential for teachers' social interactions to widen access for underrepresented groups. Thus, unlike Bourdieu's conceptualization of habitus in its original form, subsequent theoretical reinterpretations and empirical applications of habitus support a role for teachers in reducing socioeconomic disparities in educational progress.

\section{Aims of the Current Study}

Within the UK literature to date, most studies of teacher encouragement (for example, McHarg et al. 2007; Moogan 2011; Reay et al. 2001) are based on convenience samples at either a single or small set of education institutions. Consequently, the extent to which their circumstances are representative of students more broadly is ambiguous. Without more extended discussions of why a given site or sample group is of particular research interest, many of these studies forego the type of theoretical generalization that Eisenhart (2009) argues is so important to educational research methodologies. As a consequence, while habitus-based empirical studies frequently provide illuminating perspectives, the absence, to date, of inferential quantitative studies to corroborate their assertions weakens this literature's capacity to make claims about students' experiences at the national scale, which is an important consideration for policymakers.

In this study, I provide a constructive application of the principles of habitus by testing whether perceived teacher encouragement has a positive impact on students' enrollment decisions and whether any effects vary by students' socioeconomic status and achievement levels. My use of quantitative methodology extends the current literature because it facilitates the construction of a credible counterfactual, and the use of longitudinal data makes it possible to assess the impact of social interactions on observed enrollment behaviors years later. This study tries to answer the following questions:

1. If a student reports encouragement by at least one teacher to progress to the noncompulsory years of high school, does this increase the likelihood of that student enrolling in A-levels?

2. Does any impact of such encouragement extend to future enrollment in a university degree course?

3. For both enrollment in A-levels and enrollment in a university degree course, does the impact of perceived teacher encouragement vary by parental education or students' prior academic achievement?

Although I use Bourdieu's concept of habitus to theorize class disparities in access and choice, my empirical strategy is markedly different from the norms of the habitus literature in England. More specifically, I use a quantitative estimation approach rather than the more common qualitative approaches of interviews, focus groups, and ethnographic observation, and, as a consequence, I relinquish affordances of those approaches. For example, with qualitative methods, researchers have been able to provide phenomenological studies that represent students' decision-making in a nuanced, heterogeneous manner.

In contrast, I use a straightforward measure of students' perceived encouragement from teachers, and link the impact of this encouragement to observed enrollment behavior in subsequent years. The measure is a closed survey question from the Longitudinal Study of Young People in England (LSYPE): did they [the teacher] tell you [the student] that they thought you should stay on in full-time education? Thus, it can only examine a single 
dimension of teacher interactions with students, and in a narrow manner. Students answered this survey question during the same school year to which the question relates (i.e., tenth grade), and it can refer to any teacher in their school.

In the research literature though, no standard approach has yet been accepted for operationalizing either teacher encouragement or support. What these studies do generally have in common is a focus on students' perceptions. Reay et al. (2001) define teacher encouragement as persuading students that there are benefits to staying in higher education. Moogan (2011) discusses teacher encouragement in terms of teachers sharing information about their own experiences in higher education, as well as information about the type of school attainment necessary in order to make feasible a particular choice of subject major at university. McHarg et al. (2007) treat support as a teacher telling students they should continue to post-compulsory education and provides information about whether they are likely to get the requisite grades. Among quantitative studies, Berzin (2010) uses a scale based on 11 questions asked of students about teacher support, but does not specify what these questions are. In their study of student aspirations, Anders and Micklewright (2013) use the same question that I use in this study.

Some potential sources of bias in this measure of encouragement should be noted.

One challenge is that students' interpretation of the question might vary systematically according to prior characteristics such as self-worth, aspirations, and prior attainment. For example, students who are more confident may be more likely to interpret the same interaction with a teacher as encouragement, and also more likely to progress to university. A similar but distinct challenge is recall bias: students may be consistent in how they interpret an interaction but differ in their reporting of it. Again, this might differ according to background characteristics. For example, students who enjoy school may be more likely to report instances of teacher encouragement than might those students who feel more disillusioned about school, and differing attitudes to school are also likely to be linked to progress to university. Such systematic differences in interpretation and response bias increase the risk of spurious estimations of teacher encouragement, especially when they occur according to unobservable characteristics that cannot be accounted for in the matching process.

\section{The Empirical Model}

I work from the assumption that it is implausible that teachers randomly choose which students to encourage to continue to the final years of schooling. To take one example, on average teachers are more likely to provide encouragement to students with higher prior attainment (Franklin 1995; McHarg et al. 2007). Since attainment is also positively correlated with university attendance, a simple comparison between those who do and do not receive encouragement risks overestimating the impact of encouragement on enrollment. However, controlling for attainment alone would be insufficient: there are multiple other potential sources of bias, for example social class and ethnicity, that could be correlated with both university enrollment and teacher perceptions of students' ability to benefit from post-compulsory education. Nonetheless, my hypothesis is that, even after accounting for multiple sources of such selection bias, students who receive encouragement from teachers are more likely to progress to university than those who do not.

My goal is to identify the average impact of encouragement on those students who received encouragement, i.e., the average effect of treatment on the treated (ATT). This is 
achieved by comparing their educational outcomes to an estimate of what would have happened if those same students had not been encouraged. The reason for targeting this, rather than the average impact for all students (even those who did not receive encouragement), is that teacher encouragement is not randomly assigned, and so an estimation of the impact of encouragement on all students may be less plausible and so have fewer practical implications. In addition, it may not be feasible or desirable for teachers to encourage all students to continue to the non-compulsory years of high school.

The ATT is formally identified as:

$$
\mathrm{ATT}=E\left(Y_{1} \mid T=1\right)-E\left(Y_{0} \mid T=1\right),
$$

where $E\left(Y_{1} \mid T=1\right)$ represents the probability that an outcome, $Y$, will occur for those students receiving a 'treatment', $T$; in the case of this paper, it is the observed enrollment outcome for those students who received encouragement. The second part of the right-hand side, $E\left(Y_{0} \mid T=1\right)$, represents the probability that that outcome would have occurred if those same students had not received the treatment; in the case of this paper, it is the hypothetical enrollment outcome for those same students if they had not received encouragement. This is the counterfactual, i.e., the unobserved outcome.

I attempt to provide a reliable estimate of this counterfactual through the use of propensity score matching. Instead of comparing individuals across multiple characteristics, the approach matches on a single dimension: the probability of receiving encouragement (Rubin 1997). As Rosenbaum and Rubin (1983) have demonstrated, matching on the probability of covariate occurrence is equivalent to directly matching on covariate existence.

Using a set of predictors, I estimate a logistic regression model to determine each student's propensity score, i.e., the probability of receiving encouragement:

$$
\log \frac{P_{s}}{1-P_{s}}=\alpha+\beta_{1} X_{1 s}+\beta_{2} X_{2 s}+\cdots+\beta_{k} X_{k s}+\int_{s}
$$

where $P_{s}$ is the estimated propensity score for student $s, \alpha$ and $\beta_{1}$ through $\beta_{k}$ are estimated coefficients, $X_{1}$ to $X_{k}$ are a range of observed background characteristics, and $\varepsilon_{s}$ represents a random error term that is logistically distributed. This model is estimated with the LSYPE's survey weights, and standard errors are clustered at the level of schools. Each student's propensity score is estimated once and then used in all subsequent matching models.

After estimating each student's propensity score, I derive the ATT through kernel-based matching, as developed by Heckman, Ichimura and Todd (1998). Evidence suggests that the kernel approach to matching is more precise than the most common alternatives, radius and one-to-one matching (Frolich 2004). Kernel matching is a non-parametric estimation approach that uses multiple observations from the comparison students (in this analysis, those who do not report receiving encouragement) to generate the counterfactual for each student who did report receiving encouragement.

The ATT for matching methods is represented by

$$
A T T=\frac{1}{n_{1}} \sum_{i \in(T=1)}\left(Y_{i 1}-\sum_{j \in(T=0)} w(i, j) Y_{0 j}\right)
$$

where $n_{1}$ is the number of students who report encouragement, $j$ is the given student who did not report encouragement, and $w(i, j)$ is the weight placed on each student who did not 
report encouragement (unit $j$ ) for a student who did report encouragement (unit $i$ ). I define this weight according to a kernel function,

$$
K(\phi), \phi=\frac{\left(\frac{P_{i}(X)}{1-P_{i}(X)}\right)-\left(\frac{P_{j}(X)}{1-P_{j}(X)}\right)}{h}
$$

in which $\phi$ represents the quality of the match. This quality of match is calculated by taking the difference between the odds ratio of the propensity score for the student who reported encouragement $\left(S_{i}\right)$ and the odds ratio of the propensity score for the student who did not $\left(S_{j}\right)$, as a proportion of a bandwidth $h$.

Using this kernel function then, the weight for a given student who did not report encouragement is

$$
w(i, j)=\frac{K(\phi)}{\sum_{j} K(\phi)}
$$

That is, each kernel weight for the given observation $j$ must be divided by the sum of the kernel weights in order for the matching weights $w(i, j)$ to sum to one. Consequently, the kernel-based matching approach requires choices with regards to the type of kernel function $(K)$ and bandwidth size $(h)$, with the former typically proving less important than the latter (Caliendo and Kopeinig 2008). I use the Epanechnikov kernel function, which strikes a balance between prioritizing those comparison students with the most similar propensities while still incorporating the results for a broad range of comparison students (Reynolds and DesJardins 2009). ${ }^{6}$

Choice of bandwidth size is essentially a tradeoff between limiting bias, which increases as bandwidth increases, and limiting variance, which increases as bandwidth decreases. I estimate models with bandwidths between 0.1 and 0.11 , meaning that for a given student who reports encouragement the comparison match is derived from comparison students whose propensity score fell within 0.05 and 0.055 on either side of the score of the student who reported encouragement. This choice of bandwidth provides the greatest covariate balance between those who received encouragement and the matched comparison students, which is an important prerequisite for the matching procedure to maintain validity (Guo and Fraser 2010).

\section{Data}

I use data from the UK Department of Education's LSYPE (Department for Education and National Centre for Social Research 2012). ${ }^{7}$ The LSYPE used a two-stage probability proportional to size sampling procedure. The primary sampling units were schools, of which 647 were surveyed during the first wave. Respondents were born between September 1, 1989 and August 31, 1990, and were interviewed annually between 2003, at which point they were in eighth grade, and 2010. Religious, ethnic and linguistic minorities

\footnotetext{
${ }^{6}$ I also estimate models with alternate kernel types-uniform, normal and biweight-in order to test each model's sensitivity to this choice. Results, which are compiled in "Appendix 3: Alternative Model Specifications" section, indicate that results estimated with the Epanechnikov kernel are typically more conservative than those with the other kernel types.

7 LSYPE's sampling frame is representative of students living in England, but not any of the UK's other constituent countries.
} 
were 'oversampled' in proportion to the English population. I use the survey's population weights in order to account for this 'oversampling,' differential response rates across waves, and the use of clustered sampling within schools.

As with most longitudinal surveys, the LSYPE is prone to sample attrition (Anders 2012a; Piesse and Kalton 2009). The first wave of LSYPE interviews sampled 15,770 respondents in 2003; by the seventh and final wave in 2010, the number of participants had fallen to 8682. Sample attrition is further exacerbated by item non-response among surveyed respondents. Item non-response is especially important to the current study because propensity-score matching relies on accounting for a broad range of background factors via observed variables, thus increasing the incidence of observations with missing responses in comparison to more parsimonious models.

I mitigate this somewhat by only using items from the interviews with the primary parent or caregiver, rather than also using corroborative items from interviews with the secondary parent or caregiver; this avoids the loss of an additional $9 \%$ of respondents. For those respondents for whom there were still missing variables, I use listwise deletion, which yields approximately unbiased coefficient estimates even when data is not missing at random (Little 1992). This left a restricted sample of 4300 respondents. "Appendix 1: Missing data" section provides further details about the choice to use listwise deletion as well as patterns of attrition and non-response rates on specific variables. Table 1 presents a full range of descriptive statistics for the restricted sample, after the requisite adjustment for population weights.

Still, attrition and non-response pose a number of challenges to this study. The first is a loss of efficiency: as sample size reduces, standard errors for the coefficients in a given ATT estimate will increase (Goldstein 2009). The impact of this reduced precision is that, should perceived teacher encouragement have an impact on students' education outcomes, model estimates would be less likely to identify this. However, the restricted sample size (4300 students) is still considerable, and the greater concern in most ATT estimates in the social sciences is a false positive, i.e., mistakenly claiming that a difference exists between groups, rather than a false negative, i.e., mistakenly failing to identify a difference between groups.

The second, and more consequential, challenge relates to the model's external validity. Unless attrition and item non-response are occurring at random among the sample, the subset of students who continued to participate in LSYPE is less representative of all students in England than the initial, larger group of students who participated in LSYPE's first wave. Fortunately, because LSYPE is linked to administrative exam data, it is possible to compare subsequent attainment in national examinations between my restricted sample and the full LSYPE sample (details are presented in "Appendix 1: Missing data" section, Table 5). The restricted sample performed significantly better than the full sample in fifth-, eighth-, and tenth-grade examinations, making clear that attrition and non-response are not occurring at random.

Focusing first on the observable difference in achievement between the groups, overall ATT estimates should thus not be taken as accurate point estimates for the full LSYPE cohort, but rather as indicative of trends found in a group with an above-average distribution of achievement. Another concern though is not only that attrition and non-response are more common among respondents with lower educational attainment, but that within this group attrition and non-response occurs more frequently in relation to factors that are not captured in the matching models and are thus unobserved. For example, if more motivated students among lower achievers were more likely to continue with LSYPE and also more likely to respond positively to teacher encouragement, then model estimates 
Table 1 Descriptive statistics for sample

\begin{tabular}{|c|c|c|c|}
\hline & $\begin{array}{l}\% \text { or Mean } \\
(\mathrm{SD})\end{array}$ & & $\begin{array}{l}\% \text { or Mean } \\
(\mathrm{SD})\end{array}$ \\
\hline Enroll in university & 0.45 & $\begin{array}{l}\text { Parent predict child continues past } \\
\text { 10th grade }\end{array}$ & 0.83 \\
\hline \multirow[t]{2}{*}{ Teacher encouragement } & 0.48 & Parent saving for university & 0.27 \\
\hline & & Home Internet & 0.91 \\
\hline Region & & Religion & \\
\hline Northwest & 0.14 & Christian & 0.58 \\
\hline York Humber & 0.11 & Muslim & 0.03 \\
\hline East Midlands & 0.09 & Hindu & 0.01 \\
\hline West Midlands & 0.12 & Sikh & 0.01 \\
\hline East & 0.11 & Other & 0.01 \\
\hline London & 0.10 & None & 0.37 \\
\hline Southeast & 0.16 & Religiosity $(1=$ high, $4=$ low $)$ & $3.1(1.0)$ \\
\hline Southwest & 0.11 & Academic aptitude & \\
\hline Rural area & 0.22 & 5th grade English & $27.4(4.0)$ \\
\hline IDACI score & $0.18(0.16)$ & 5 th grade math & $27.4(4.6)$ \\
\hline Household income & $34,234(29,738)$ & 5th grade science & $28.9(3.4)$ \\
\hline Parent education & & 8th grade English & $34.7(5.7)$ \\
\hline $\begin{array}{r}\text { No educational } \\
\text { qualifications }\end{array}$ & 0.07 & 8 th grade math & $37.4(7.3)$ \\
\hline Sub-10th grade qualification & 0.05 & 8th grade science & $34.8(6.2)$ \\
\hline 10th grade qualification & 0.25 & Female & 0.51 \\
\hline 12th grade qualification & 0.20 & Racial/ethnic identity & \\
\hline Post-high school, not degree & 0.18 & Afro-Caribbean & 0.04 \\
\hline University degree & 0.19 & South Asian & 0.06 \\
\hline $\begin{array}{l}\text { Parent occupational status } \\
\text { (NSSEC) }\end{array}$ & & Other minority & 0.01 \\
\hline High & 0.47 & English foreign language & 0.03 \\
\hline Medium & 0.28 & British-born & 0.96 \\
\hline Low & 0.14 & Aware of EMA policy & 0.64 \\
\hline $\begin{array}{l}\text { Parent long-term } \\
\text { unemployed }\end{array}$ & 0.11 & Free school meals & 0.09 \\
\hline$N$ & 4300 & Special educational needs & 0.18 \\
\hline
\end{tabular}

would not be truly representative of all lower achieving LSYPE respondents and would overestimate the impact of teacher encouragement.

This is certainly a plausible concern, and subsequent model estimates should be interpreted with this in mind. Since it is based on unobserved factors though, the scale of this challenge is inherently unknowable. Non-random missing data problems are a common challenge in social sciences (Allison 2002), but, because of attrition, are especially problematic for longitudinal data analysis (Alderman et al. 2001; Goldstein 2009; Molenberghs and Fitzmaurice 2008). The challenges stated here are thus an important but necessary tradeoff for the benefits afforded by longitudinal data (namely, detailed background information and longer-term outcomes). 


\section{Model Variables}

\section{Outcomes of Interest}

This analysis focuses on two outcomes, each of which is self-reported and operationalized by a dichotomous dummy variable. The first is a given student's enrollment in A-levels within two years of completing compulsory education (i.e., within two years of completing tenth grade). The second is enrollment in a university-degree course at ages $18-20{ }^{8}$ This outcome is considered for all students, not only those who enrolled in A-levels.

\section{Key Explanatory Variable}

The key explanatory variable of interest is whether a given student reported receiving encouragement from schoolteachers to continue to A-levels. This measure is operationalized as a student's self-report during tenth grade (the final compulsory year of schooling) of whether they recall any teacher encouraging them to continue to A-levels. This question was asked of all students taking part in the survey. The variable is dichotomous, with students either reporting encouragement from one or more teachers, or not at all.

\section{Model Controls}

Because my aim is not simply to establish an association but a potential cause and effect, it is important to account for other factors that are linked both to schoolteacher encouragement and progression to postsecondary education. In propensity-score matching, this is done through the explanatory variables used to generate each individual's propensity score, as per Eq. 2. Informed by the research literature on university participation in England, the variables that I select can be grouped into four main categories: (1) finances, (2) academic achievement, (3) social class, and (4) elements of ethnic, religious, and gender identity. All variables are measured during LSYPE's first two survey waves, which ensures that the explanatory variables are not dependent on teacher encouragement in tenth grade.

\section{Finances}

Students from poorer households are especially likely to be intimidated by the costs of attending university (Pennell and West 2005); while they tend to be knowledge about fees, they are far less likely to know about the range of scholarships and bursaries available to offset these (Chowdry et al. 2012; Christie and Munro 2003), especially among those without home access to the internet (Gorard and Selwyn 1999; Lee 2008). This is further exacerbated by geographic disparities: those living in more isolated regions, especially in rural areas, face greater travel and accommodation costs when attending university (Gibbons and Vignoles 2012; Harrison 2013). Consequently, I estimate models controlling for household income, whether parents are saving for university, region, urbanicity,

\footnotetext{
8 "Universities" refer to the 119 institutions awarded university status by the United Kingdom Government (2012). They are broadly equivalent to four-year colleges in the US, although a university degree in the UK typically requires three years of full-time study. While the sample includes accredited private and for-profit universities, the great majority (111) are public institutions.
} 
neighborhood poverty (with the Income Deprivation Affecting Children Index (IDACI)), and internet access.

\section{Academic Achievement}

Socioeconomic disparities in higher education participation drop considerably when accounting for educational achievement (Anders 2012b; Chowdry et al. 2008; GalindoRueda et al. 2004). Academic achievement controls consist of students' test scores in six national examinations: English, science, and mathematics during the fifth grade and the same subjects again during the eighth grade.

\section{Social Class}

The importance of social class has been discussed in more detail earlier in this manuscript, and there is evidence that its impact on university access cannot be accounted for solely by other measures (Ball et al. 2002a; Jackson 2011; Jackson and Jonsson 2013). Social class variables consist of the main parent or caregiver's occupational class (as defined by the National Statistics Socio-Economic Classification (NSSEC) system), education, and whether she expected the student to continue to non-compulsory education (asked when the student was in ninth grade).

\section{Racial and Ethnic Identity Controls}

Many researchers have expanded Bourdieu's (1998) theorization of habitus to examine the role of racial, ethnic, and religious identity in forming students' beliefs about higher education in England (see, for example, Adnett and Tlupova 2007; Archer et al. 2001; Archer and Leathwood 2003; Ball 2008; Burke 2010). Model controls are used for students' self-designation into racial groups (White, South Asian, Afro-Caribbean, and all other designations), whether the student speaks a language other than English in their household, and religion (Christian, Muslim, Hindu, Sikh, other, and none).

\section{Findings}

\section{Descriptive Statistics}

Table 2 provides a comparison of background characteristics between those students who reported encouragement (column titled "Report encouragement") and students who do not (column titled "All who do not"). Many of these characteristics differ significantly between the groups: broadly speaking, it appears that students who receive encouragement are, on average, more advantaged than those who do not. For example, $22 \%$ of students receiving encouragement have a parent with a university degree, compared to $15 \%$ of those who do not. Similarly, students who do not report encouragement are a third more likely to have an unemployed parent (12 vs. 9\%) and score worse on average on every one of the fifth and eighth grade national examinations. While it is plausible that teachers are not encouraging some students because it is a moot point-i.e., some students seem certain to go to university anyway-the greater absence of encouragement is for those whose backgrounds suggest they are less likely than average to reach higher education. These 


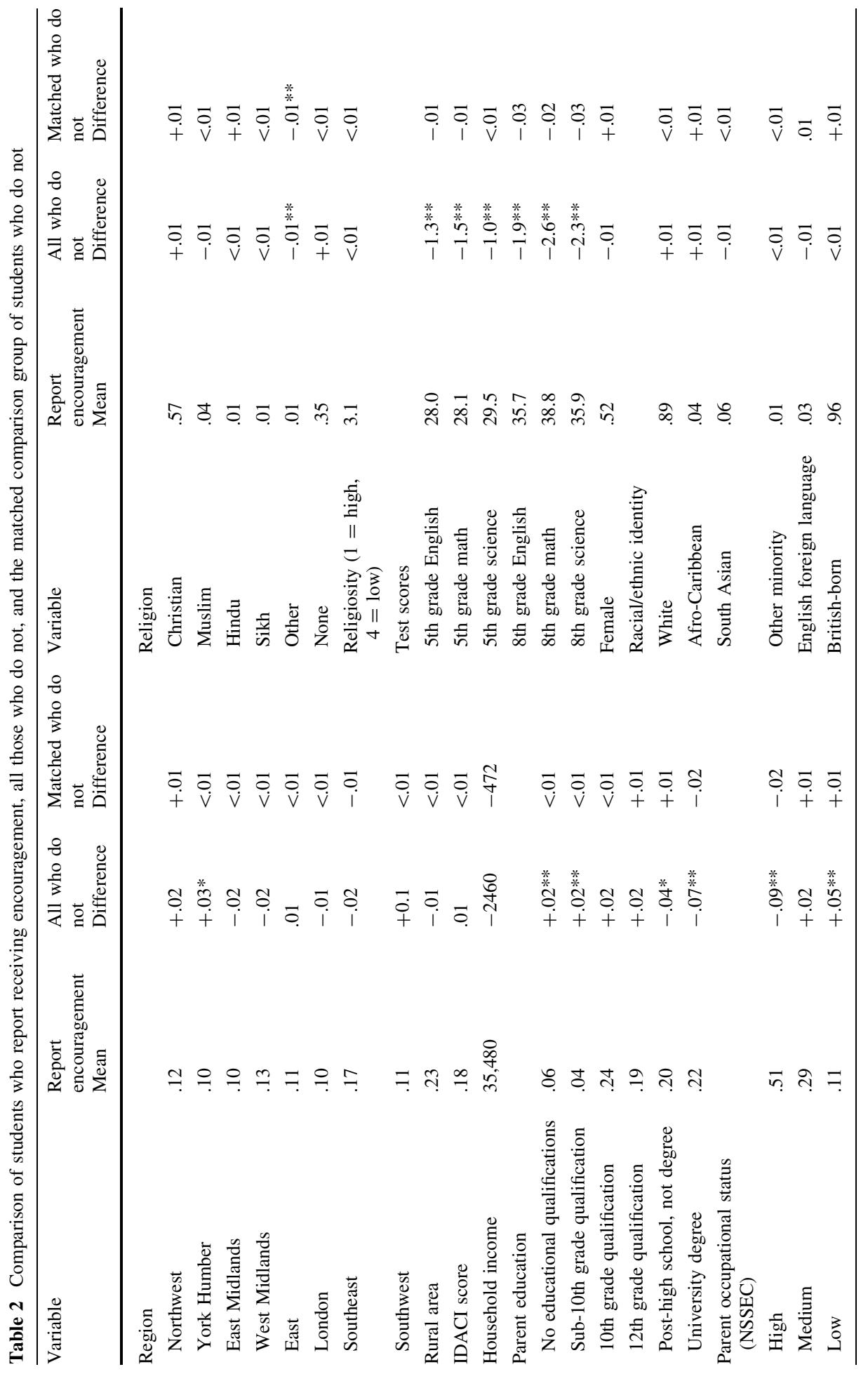




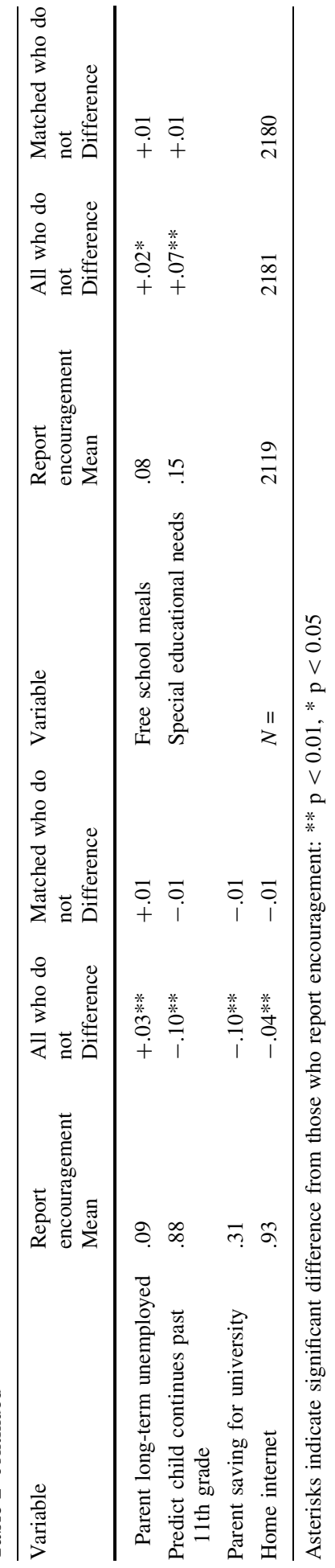


differences confirm the need for an analytic strategy that can account for confounding factors, as a failure to do so is likely to overestimate the impact of teacher encouragement.

\section{Propensity Score Matching: Model Fit}

Before discussing the results of the propensity score matching models, it is important to first scrutinize the validity of the analysis, i.e., whether it has successfully accounted for such confounding factors. In order for a propensity score matching analysis to provide plausible estimates, it must adhere to three assumptions: conditional independence, common support, and covariate balance (Reynolds and DesJardins 2009).

\section{Conditional Independence}

This assumption holds that, conditional on the observed covariates used in the model, the outcome of interest is independent of whether a student receives encouragement (Rosenbaum and Rubin 1983). It is therefore paramount that the variables used to generate the propensity scores comprehensively account for potential sources of bias. Fortunately, the LSYPE dataset has sufficiently detailed information about respondents to ensure that key themes in past literature on university access in England are well represented.

Still, the dataset is not perfect, making it important to consider which unobserved variables provide potential sources of bias. Perhaps the most compelling would be information on school attended, teachers, student effort, and student motivation. When estimating students' propensity scores (Eq. 2), it was not feasible to run a school fixed effects model due to the large number of schools in the dataset with very few sampled students. Unfortunately, the LSYPE contains no information on which teacher provided a given student with encouragement, nor on any characteristics that might inform the likelihood of them doing so, such as experience, subject specialty, or attitude. While the research literature in psychology has developed a number of constructs both for measuring effort (see, for example, Marsh et al. 2003; Midgley et al. 2000; Pintrich et al. 1993) and motivation (see, for example, Baker and Wigfield 1999; Dolan 1983; Gottfried and Gottfried 1996; Vallerand et al. 1992;), none of these were collected in the LSYPE surveys.

The absence of these variables is mitigated, albeit probably only moderately, by the likelihood that they are correlated to observed variables that are used in the matching process. In the case of school effects, the IDACI neighborhood deprivation score is highly correlated to school attended: $55 \%$ of the variation in IDACI is explained by which school each student attends. This is beneficial since the IDACI score can serve somewhat as a proxy for part of the variation in school attended. While it is not possible to make similar calculations for teacher characteristics, student effort and student motivation, these are likely to correlate with a number of the variables used in this study's models, such as attainment or aspirations, although a more direct proxy of effort would further improve the study's validity.

Since the bias caused by missing variables is by definition unknown, it is not possible to know for certain whether the conditional independence assumption has been met. Still, there are empirical tools that make it possible to assess a matching model's susceptibility to their omission. The Mantel-Haenszel test (Mantel and Haenszel 1959), for example, determines how strongly the influence of an unobserved dichotomous variable would need to be in order to undermine the given model. Mantel-Haenszel tests for all matching models are presented available in "Appendix 2: Sensitivity to Omitted Variables" section. To summarize here, those that have significant non-zero findings have critical test 
statistic values of 1.55 or 1.6. This indicates that, in order for each of these models' ATT estimate to no longer be significantly different from zero, an unobserved dichotomous variable would need to cause the odds ratio of treatment assignment to differ between the treatment and comparison groups by a factor of at least 1.55 (Becker and Caliendo 2007). To provide a reference point, in the logistic regression model used to generate the propensity scores, the greatest odds ratio for any dichotomous variable was 1.5 (the variable asking whether the student's parent expected them to continue beyond GCSEs). This suggests that any such confounding variable would need to have a strong impact, independent of the existing variables, on the prediction of teacher encouragement in order to render spurious this study's model estimates.

\section{Common Support}

The common support assumption requires that there are a sufficient number of observations from each group with comparable propensity scores. Unlike standard regression approaches, propensity-score matching compels the researcher to consider the comparability of those receiving encouragement and comparison students (Blundell et al. 2005; Gasper et al. 2012). Figure 1 shows a great deal of overlap between the groups: almost every student reporting encouragement had a calculated propensity that was equivalent to that of some students in the matched control group. This was confirmed during the propensity matching estimation, which dropped just 1 of the 2181 students who did not report encouragement due to a lack of common support, indicating that this assumption has been met.

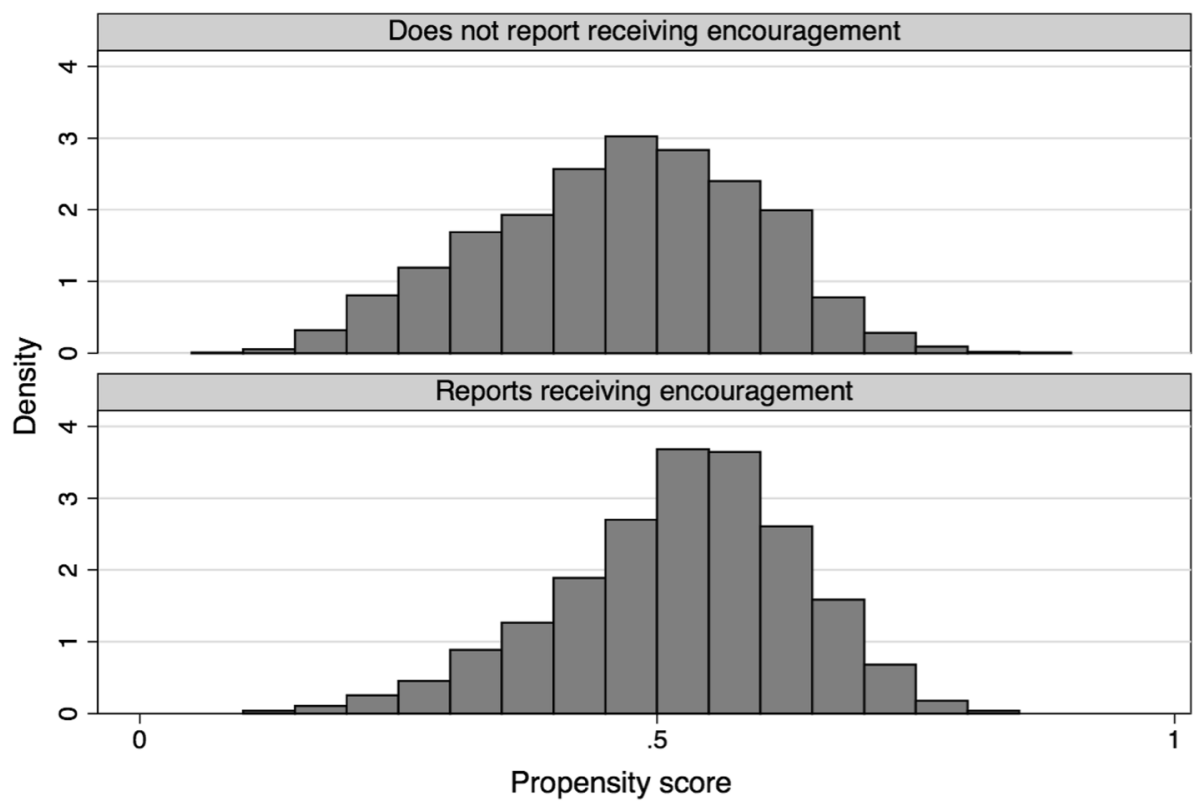

Fig. 1 Common support between students who report encouragement and those who do not 


\section{Covariate Balance}

The covariate balance assumption requires that the mean and standard deviation for each of the covariates do not differ significantly between the matched groups. Following precedents in the literature (see, for example, Reynolds and DesJardins 2009), I do this with a two-sample $t$ test of the difference in means across the groups for each of the covariates. In Table 2, model covariates are presented for the students who reported encouragement, all students who do not, and the matched comparison students who do not. It provides evidence that the analytical model meets the covariate balance assumption. When comparing students who reported encouragement to all students who did not, 20 of the 46 covariates are significantly different at the 5\% level. In contrast, just one of the 46 covariates was significantly different between students who reported encouragement and the matched comparison students, indicating that the analytical model meets the covariate balance assumption.

\section{Propensity Score Matching: Model Estimates}

My first research question asks whether perceived teacher encouragement influences enrollment in A-levels. Results for this outcome are presented in Table 3. The ATT estimate indicates that encouragement does have an impact: rates of enrollment in A-levels were $8 \%$ points higher among students who received encouragement (74\% of whom enrolled in A-levels) than among matched students who did not (66\%). While this is markedly smaller than the raw gap between all those students who do and do not report receiving encouragement (18\% points), it is still large enough to suggest that the impact of teacher encouragement is significant at any conventional level.

Further, the impact of teacher encouragement appears to vary by student background, and is greatest for students with lower levels of parental education. For those from the two lower groups (no qualifications and tenth-grade qualifications), A-level enrollment rates

Table 3 ATT estimates for impact of encouragement on enrollment in A-level study

\begin{tabular}{llll}
\hline & $\begin{array}{l}\text { Students reporting } \\
\text { encouragement }(\%)\end{array}$ & $\begin{array}{l}\text { Matched comparison } \\
\text { students }(\%)\end{array}$ & $\begin{array}{l}\text { ATT (percentage-point } \\
\text { increase) }\end{array}$ \\
\hline $\begin{array}{l}\text { All } \\
\text { Parental education }\end{array}$ & 73.9 & 66.2 & $7.7(1.5)^{* *}$ \\
No qualifications & 63.5 & 52.0 & $11.5(3.9)^{* *}$ \\
10th grade qualification & 66.7 & 53.9 & $12.8(3.1)^{* *}$ \\
12th grade qualification & 67.4 & 63.2 & $4.2(3.6)$ \\
University degree & 85.6 & 80.1 & $5.5(2.1)^{*}$ \\
Academic achievement & & & $8.4(3.3)^{*}$ \\
Lower & 35.0 & 26.6 & $11.7(2.6)^{* *}$ \\
Middle & 64.0 & 52.3 & $3.4(1.5)^{*}$ \\
Upper & 91.2 & 87.9 & \\
\hline
\end{tabular}

$* p<0.05 ; * * p<0.01$. Significance is derived from a $t$ test for equality of means between the two groups, i.e., between students reporting encouragement and matched comparison students 
increase by 12 and $13 \%$ points for those receiving encouragement, respectively, both of which are significant at the .01 level. In contrast, the effect of encouragement is far smaller for the other two groups (twelfth-grade qualifications and university degree holders), by 4 and $6 \%$ points, respectively, only the latter of which is significant at the .05 level. While the impact of encouragement is significant for all three of the achievement groupings, it is far greater for students in the lower and middle thirds.

Table 4 presents ATT estimates for the impact of encouragement on enrollment in a university degree course. Across all students, the ATT indicates that rates of enrollment are $4 \%$ points higher for students who reported encouragement than for matched comparison students, which is significant at the .01 level. And, as before, the impact of teacher encouragement varies by student background. Encouragement has a larger, significant impact among students whose parents have lower levels of education (no qualifications or tenth grade qualifications): for these groups, the estimated likelihood of university enrollment increases by 10 and 7\% points, respectively, representing an increase of about a fifth over the matched comparison students. When considering student's prior academic achievement, there is a considerable impact for the middle third, where enrollment is $10 \%$ points higher among students who received encouragement $(46 \%)$ compared to matched comparison students who did not $(36 \%)$. However, encouragement has no observable impact on students in the upper and lower thirds.

\section{Discussion}

\section{Limitations}

One key limitation of the propensity-score matching approach is its reliance on observed variables. However perfect the match on these variables between students who reported encouragement and the matched comparison students, there will always be some degree of uncertainty on the quality of matching on unobserved variables. I have sought to mitigate this shortcoming, both through guiding my selection of variables via the past literature and testing for sensitivity to omitted variables (see "Appendix 2: Sensitivity to Omitted

Table 4 ATT estimates for impact of encouragement on enrollment in a university degree course

\begin{tabular}{lllc}
\hline & $\begin{array}{l}\text { Students reporting } \\
\text { encouragement }(\%)\end{array}$ & $\begin{array}{l}\text { Matched comparison } \\
\text { students }(\%)\end{array}$ & $\begin{array}{l}\text { ATT (percentage- } \\
\text { point increase) }\end{array}$ \\
\hline All & 57.4 & 53.3 & $4.1(1.6)^{* *}$ \\
Parental education & & & $10.3(3.9)^{* *}$ \\
No qualifications & 49.4 & 39.1 & $7.3(3.1)^{*}$ \\
10th grade qualification & 45.9 & 38.6 & $3.1(3.7)$ \\
12th grade qualification & 50.9 & 47.8 & $0.1(2.5)$ \\
University degree & 70.3 & 70.1 & $4.6(2.8)$ \\
Academic achievement & & & $10.4(2.6)^{* *}$ \\
Lower & 21.7 & 17.1 & $-1.6(2.0)$ \\
Middle & 46.0 & 35.6 & 76.5 \\
Upper & 74.9 & & \\
\hline
\end{tabular}

$* p<0.05 ; * * p<0.01$. Significance is derived from a $t$ test for equality of means between the two groups, i.e., between students reporting encouragement and matched comparison students 
Variables" section). A reliance on observed variables also exacerbates the aforementioned challenges (see "Data" section) within longitudinal data of attrition and non-response, in turn limiting the extent to which the restricted matching sample is truly representative of LSYPE's original sample, and thus of students across England more broadly.

Another methodological limitation relates to the measurement of teacher encouragement, since it relies entirely on student reports. There is no means of corroborating student assessments of encouragement with the perspective of their teachers. However, while this reliance on student self-reports may encourage readers to be cautious in accepting the findings presented here, it is useful in itself to learn from students' perceptions of receiving encouragement.

Although the LSYPE cohort completed compulsory high school in 2006, it is not possible to make a straightforward extrapolation of these findings onto school students in the present day. Since 2013, England's government has made it compulsory for youth to remain some form of education or training until age 17, and in 2015 the government extended this requirement until age 18. There is not yet empirical evidence of the policy's impact on youth enrollment behavior. It is important to note though that the government's definition of education or training is broad: apprenticeships, part-time education, or training while employed suffice. The fact that I operationalize post-compulsory enrollment as studying for A-levels, the most academically rigorous option for most students, leads me to think it unlikely that these findings would now be rendered redundant by a policy change that enforces only limited levels of education or training.

Another contextual difference is that students now face higher financial barriers to continuing in education after tenth grade. LSYPE respondents had access to the Education Maintenance Allowance, which made weekly payments of up to US\$45 to low-income students who stayed in the non-compulsory years of high school. In 2011, the government replaced the Education Maintenance Allowance with the 16-19 Bursary Fund, which offers support to a far smaller proportion of students. In addition, the LSYPE cohort finished high school at a point where annual tuition fees for all English universities were set at approximately US\$4500. In contrast, this year's cohort of school leavers face varying fee levels, with an average around US\$12,000. Given these financial disincentives, both for completing A-levels and attending university, recent policy changes in England lessen the extent to which these findings can represent conditions in the present day.

\section{Contributions}

In spite of these limitations, this study contributes to the research literature on this subject. My findings corroborate Bourdieu's theorization of habitus, but also diverge from it in an important respect. By indicating that teacher encouragement is influential in students' progress to higher education, my findings substantiate the notion that students' participation in formal education is at least partially dependent on the social cues they receive that legitimize their progress. In addition, my findings support the claim that students respond differently to such cues according to social class.

However, they differ from Bourdieu and Passeron's (1990) claim that teachers are a complicit, rather than a resistant, component of an education system that perpetuates socioeconomic disparities. This is because model estimates suggest that teacher encouragement has a positive impact on future enrollment, and that this impact is greatest for students with lower socioeconomic status. As discussed earlier, research on the British education system is divided, with some emphasizing the role of teachers in perpetuating inequality (for example, Ball 2003; Preston 2003; Reay 1998) and others the role of 
teachers in resisting inequality (for example, Hollingworth and Archer 2009; Mills 2008; Oliver and Kettley 2010). My findings corroborate the latter group. Perhaps this should encourage greater optimism about the role that formal education is able to play in tackling inequality

To my knowledge, this research is the first to provide inferential analysis on the role of student-teacher interactions in university access. Since its methodology is unique among empirical applications of Bourdieu's theorization of habitus, my findings broaden the evidentiary base for proponents of this theoretical tradition. The propensity-score model estimates suggest a sustained benefit to students when they receive teacher encouragement to commit to further education. The outcome is separated from the reported encouragement by around three to four years, yet significant benefits can be observed for recipients of encouragement. These findings add to the research literature by providing more robust evidence that near-immediate effects of teacher encouragement may also enjoy a degree of longevity.

For policy researchers whose focus is university access, it should be informative to receive inferential evidence that relations between students and their high school teachers play a role in the decision to continue in postsecondary education. University access policies ought not to conceptualize teachers solely as deliverers of course material and thus academic preparedness, envisaging family and counselors as the significant adults in influencing students' career planning and aspirations. Instead, access policies stand to benefit from accounting for the relational aspects of teacher-student interactions. From the perspective of many students, teachers are likely to represent the most immediate embodiment of the educational system through which they are navigating. Even in the early years of high school, encouragement and support from this source appears to influence the likelihood of students making the transition into the non-compulsory stages of the K-16 'pipeline'.

Policy researchers may also take interest in the evidence of heterogeneous effects not only according to socioeconomic status but also to prior attainment. This evidence helps to identify which students are most likely to be influenced. I find that the impact of teacher encouragement on enrollment in A-levels and university degrees are greatest for students in the middle tercile of attainment; this suggests that teacher encouragement has the most impact on enrollment behavior among those on the margin of continuing to non-compulsory education. This finding corroborates past research emphasizing the importance of prior attainment to university access (for example, Anders 2012b; Chowdry et al. 2013; Marcenaro-Gutierrez et al. 2007). It appears that students with middling attainment are often on the verge of continuing in education; they are more uncertain than those with higher attainment (who are sure they should continue) or those with lower attainment (who are sure they should not continue). Teacher encouragement seems to offer an effective means to improve enrollment rates among these marginal students.

This study's findings should also be of interest to schoolteachers and policymakers. Its most straightforward, but arguably important, implication is for teachers: if their encouragement is having an observable impact on future educational outcomes for students, this information should be shared with them. Many teachers are taking the initiative to encourage students to progress with education beyond the stages in which they will work directly with them, but it is unclear whether they know that this is having an impact. Still, it is worth reiterating that I estimate the average treatment effect on the treated, which only estimates the average impact of encouragement on those who received it, and does not attempt a broader estimate of the impact of encouragement on those students who do not report receiving it. Hence, it would be unreasonable to extrapolate this study's model estimates to all children or to conclude that teachers should start providing encouragement as widely as possible. Nonetheless, if this manuscript's findings confirm to teachers the 
importance of their encouragement to students, this may induce positive feedback loops in their behavior.

I began by discussing the importance of recognizing the dominance of some trends in policymaking, and the relative diminution of others. It is in this respect that this study might inform the work of policymakers. Britain's current coalition government has emphasized schooling as its main policy focus for improving educational opportunity and access to higher education. This is logical: as mentioned earlier, university access disparities by socioeconomic group are high, but close to non-existent when only considering those who complete A-levels. However, within the broad topic of schooling policy, academic attainment has received almost the entirety of the government's attention. Further, policymakers predominantly discuss teachers' ability to raise academic attainment by improving pedagogy and discipline.

The mechanisms by which teachers can improve university access are thus bounded at two levels: what they can contribute (improving academic attainment), and how they can do this (pedagogy and discipline). While policy necessitates prioritization, this conception of teachers is reductionist. Course delivery and classroom management offer important but not definitive sources of focus; teachers also have the opportunity to develop a more relational role, providing a personal intermediary between student and educational system. My findings suggest that students are responsive to non-formal cues and legitimation; as the primary figureheads of formal education, teachers may have more forms of influencing inequality than currently appreciated.

Acknowledgements I wish to thank Brian McCall, Stephen DesJardins, Julie Posselt, Anna Vignoles, Robert Axelrod, Jan Lawrence, Kelly Slay, Joe Howard, Molly Kleinman, Meredith Billings, Jake Anders, Tammy Campbell, Peter Keen, William Doyle, and two anonymous referees for their valuable feedback and thoughtful comments in the writing of this manuscript.

Open Access This article is distributed under the terms of the Creative Commons Attribution 4.0 International License (http://creativecommons.org/licenses/by/4.0/), which permits unrestricted use, distribution, and reproduction in any medium, provided you give appropriate credit to the original author(s) and the source, provide a link to the Creative Commons license, and indicate if changes were made.

\section{Appendix 1: Missing Data}

Given that my sample is restricted by missing responses, it is not possible to check the comparability of the restricted and full samples across a broad range of respondent characteristics. However, because the LSYPE is linked to the government's National Pupil Database, it is possible to compare attainment in national examinations between my restricted sample and the full LSYPE sample, as presented in Table 5. The restricted sample performed significantly better than the full sample in examinations at all three time points, indicating that the restricted sample is not directly representative of the full sample.

Also, as with most longitudinal surveys, the LSYPE is prone not only to sample attrition but also to missing components - in particular, non-participation from parents-and item non-response (Piesse and Kalton 2009). I mitigate the challenge of missing parent-interview data somewhat by only using items from the interviews with the primary parent or caregiver, rather than also using corroborative items from interviews with the secondary parent or caregiver, thus avoiding the chance of losing an additional $9 \%$ of respondents.

For the outcomes of interest, item non-response was lower than $1 \%$ for both the questions relating to A-level study $(0.91 \%)$ and university attendance $(0.21 \%)$, indicating that missing data for this variable almost entirely reflects attrition (Anders 2012a). For all 
Table 5 Comparison of restricted and full samples

\begin{tabular}{|c|c|c|c|c|c|}
\hline & \multicolumn{2}{|c|}{ Restricted sample } & \multicolumn{2}{|l|}{ Full sample } & \multirow[t]{2}{*}{ Difference in means } \\
\hline & Mean (SD) & $n$ & Mean (SD) & $n$ & \\
\hline \multicolumn{6}{|l|}{ National examinations at: } \\
\hline Fifth grade (key stage 2 average) & $27.9(3.6)$ & 4300 & $27.1(4.1)$ & 14,559 & $0.8^{*}$ \\
\hline Eighth grade (key stage 3 average) & $35.7(6.0)$ & 4300 & $33.8(6.8)$ & 14,828 & $1.9 * * *$ \\
\hline Tenth grade (GCSE capped points) & $326.5(83.8)$ & 4300 & $295.6(111)$ & 15,329 & $30.9 * * *$ \\
\hline
\end{tabular}

Asterisks indicate significant difference in means between samples: * $\mathrm{p}<0.1$, ** $\mathrm{p}<0.05$, *** $\mathrm{p}<0.01$

variables, missing values were not fully nested within missing values for any other variable, with the exception of the geographic variables (region, neighborhood wealth, and urbanicity), all of which are generated from the same base variable (postal code). As Table 7 indicates, non-response is especially high for the family-income and National Statistics Socio-economics Classification (NSSEC) variables, two characteristics that are highly correlated both with academic progression and to one another (Piesse and Kalton 2009). Analyses indicated that missingness for either variable was strongly associated with progression to higher education and was therefore not occurring at random.

Since item non-response was particularly high for only two covariates, it might be tempting to create dummy variables to identify non-response for these respective covariates in order to hold the cases with missing data. However, while this approach would help

Table 6 Percentage of observations missing each variable, by outcome

\begin{tabular}{lll}
\hline Variable & A levels $\mathrm{n}=11,823$ & University $\mathrm{n}=8664$ \\
\hline Encouragement & 4.1 & 2.8 \\
Government Office Region & 3.2 & 2.3 \\
IDACI score & 3.2 & 2.3 \\
Urbanicity & 3.2 & 2.3 \\
Family income & 25.7 & 24.6 \\
Parental education & 5.2 & 4.7 \\
Parental NSSEC & 18.9 & 9.6 \\
Parental aspirations & 4.1 & 3.3 \\
Saving for HE & 3.6 & 2.5 \\
Internet access & 2.1 & 1.1 \\
Religion & 4.1 & 3.0 \\
KS2 English & 6.4 & 5.5 \\
KS2 Math & 6.2 & 5.4 \\
KS2 Science & 6.4 & 5.6 \\
KS3 English & 7.1 & 6.7 \\
KS3 Math & 5.3 & 5.0 \\
KS3 Science & 6.3 & 6.0 \\
Gender & 0.1 & 0.0 \\
Race/ethnicity & 4.2 & 3.1 \\
Gender & 4.8 & 4.9 \\
Special educational needs & 4.3 & 3.4 \\
\hline
\end{tabular}









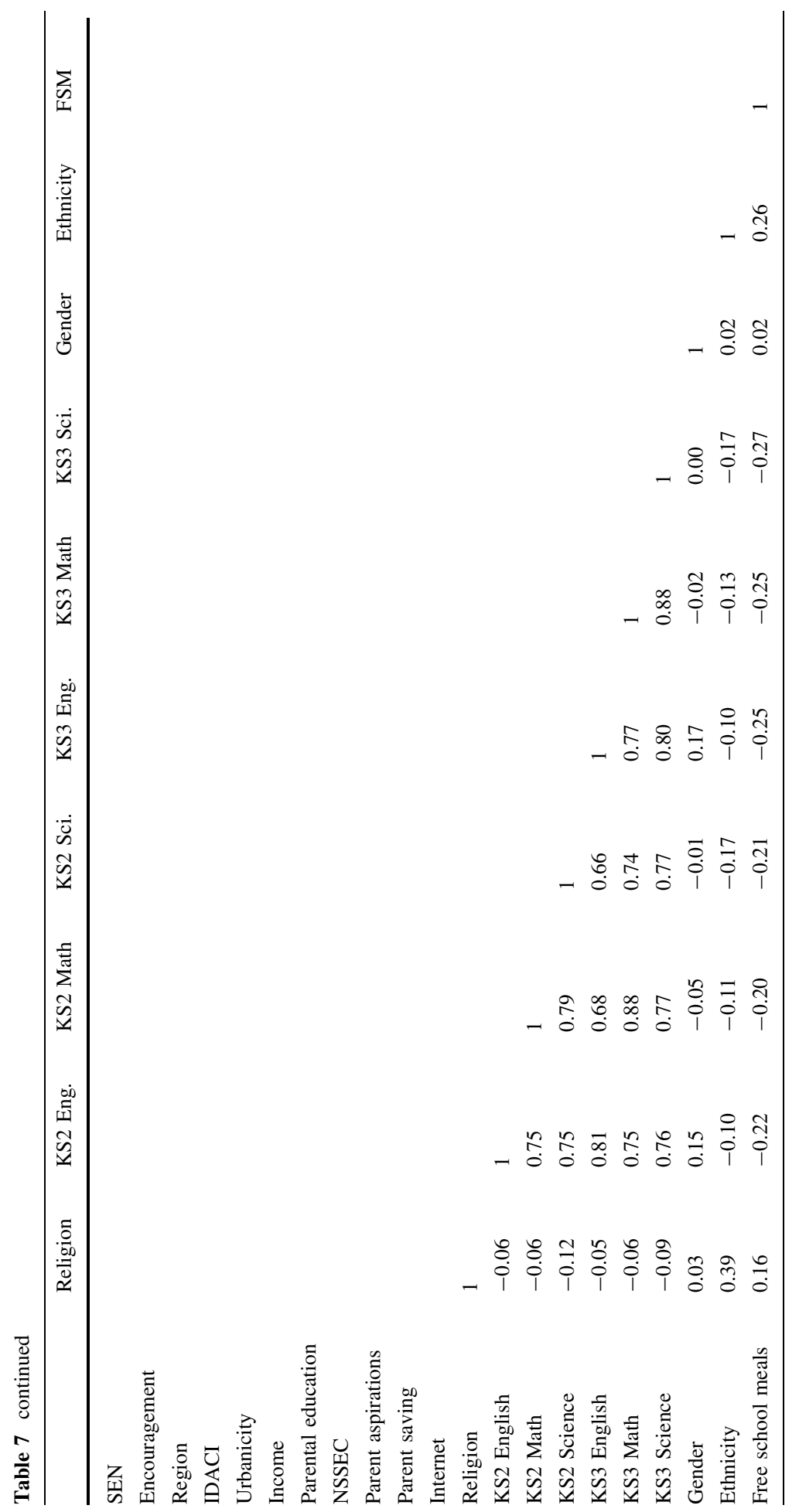




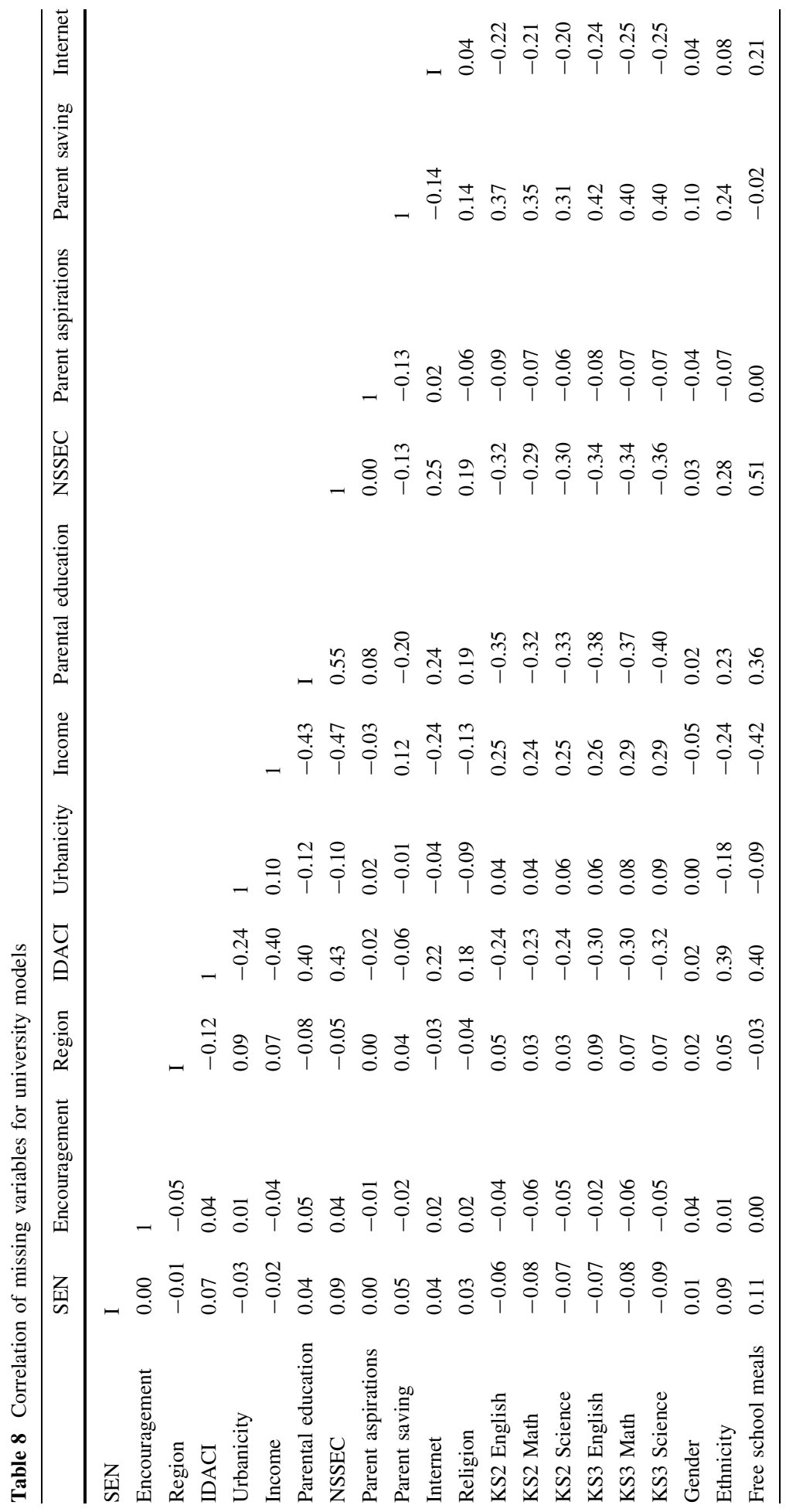




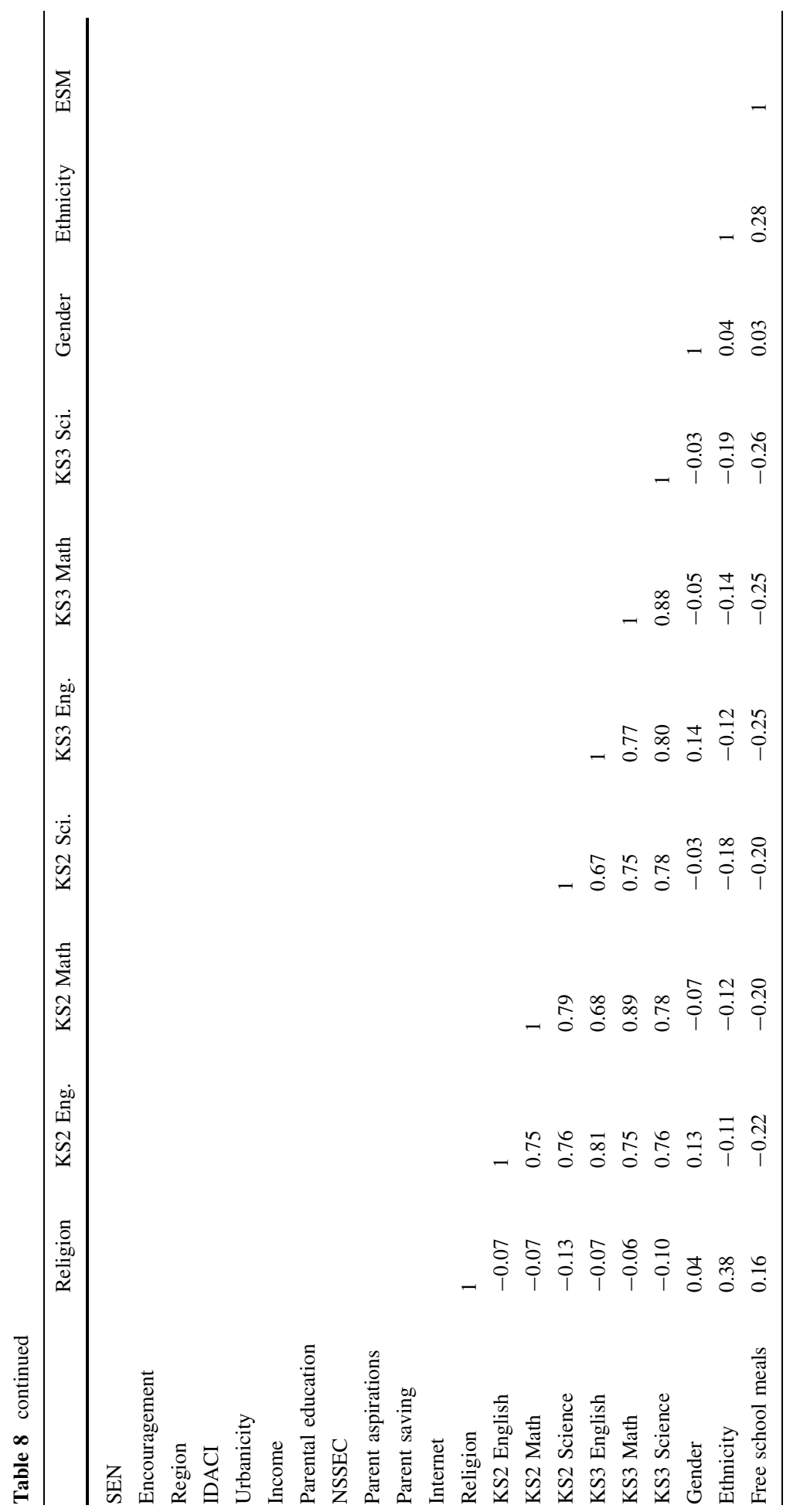


Table 9 Mantel-Haenszel test results for each model

\begin{tabular}{|c|c|c|c|}
\hline Outcome & Subsample & Bandwidth & Sensitivity \\
\hline \multirow[t]{2}{*}{ A-level study } & All & 0.11 & 1.6 \\
\hline & Parent/caregiver holds & & \\
\hline A-level study & No qualifications & 0.11 & 1.55 \\
\hline A-level study & 10th grade qualification & 0.11 & 1.4 \\
\hline A-level study & 12th grade qualification & 0.11 & 1.35 \\
\hline \multirow[t]{2}{*}{ A-level study } & University degree & 0.11 & 1.25 \\
\hline & Academic achievement & & \\
\hline A-level study & Lower & 0.11 & 1.3 \\
\hline A-level study & Middle & 0.11 & 1.6 \\
\hline A-level study & Upper & 0.11 & 1 \\
\hline \multirow[t]{2}{*}{ Attends university } & All & 0.1 & 1.6 \\
\hline & Parent/caregiver holds & & \\
\hline Attends university & No qualifications & 0.1 & 1.55 \\
\hline Attends university & 10th grade qualification & 0.1 & 1.55 \\
\hline Attends university & 12th grade qualification & 0.1 & 1.35 \\
\hline \multirow[t]{2}{*}{ Attends university } & University degree & 0.1 & 1.25 \\
\hline & Academic achievement & & \\
\hline Attends university & Lower & 0.1 & 1.1 \\
\hline Attends university & Middle & 0.1 & 1.6 \\
\hline Attends university & Upper & 0.1 & 1 \\
\hline
\end{tabular}

All models use kernel matching with the Epanechnikov kernel. The "Sensitivity" column presents the critical value at which the Mantel-Haenszel (Mantel and Haenszel 1959) test statistic's significance level exceeds the 0.05 level

to maintain sample size, any subsequent estimated models are likely to produce biased coefficients (Jones 1996), and even original proponents of dummy non-response now reject this approach (Cohen et al. 2003). Instead, I use listwise deletion, which yields approximately unbiased coefficient estimates even when data is not missing at random (Little 1992). The main weakness of listwise deletion is the loss of sample. Yet, while the resulting loss of observations leads to larger standard errors, the estimated standard errors produced by models after using listwise deletion tend to provide accurate estimates of true standard errors, making listwise deletion an "honest" approach to managing item nonresponse (Allison 2002).

For each row variable, Table 6 presents the percentage of respondents with missing information for a given variable when model-outcome variables were observed. Table 7 presents the correlation of missingness between variables when enrollment in A-levels was observed. Table 8 presents the correlation of missingness between variables for when enrollment in a university degree course was observed.

\section{Appendix 2: Sensitivity to Omitted Variables}

This appendix provides information about the bandwidth and sensitivity tests used in each matching model. All matching models were produced using kernel matching with the Epanechnikov kernel, and Table 9 presents information about the bandwidth used for each 
matching model (for a more detailed discussion of kernel and bandwidth choice, see Reynolds and DesJardins 2009).

Stata's mhbounds program (Becker and Caliendo 2007) was used to calculate the Mantel-Haenszel test statistic (Mantel and Haenszel 1959) for each model. This statistic tests a model's sensitivity to confounding factors, i.e., unobserved variables that might influence both assignment to encouragement and the likelihood of attending university. The Mantel-Haenszel test determines how strongly the influence of an unobserved dichotomous variable would need to be in order to undermine the given model. In the following table, each model's sensitivity is reported in terms of the critical value at which the Mantel-Haenszel test statistic significance level exceeds the 0.05 level. For example, the first model's critical test statistic value is 1.6. This indicates that, in order for the $95 \%$ confidence interval of the model's ATT to include zero, an unobserved dichotomous variable would need to cause the odds ratio of treatment assignment to differ between the treatment and comparison groups by a factor of 1.6 (Becker and Caliendo 2007). To provide a reference point, in the logistic regression model used to generate the propensity scores, the greatest odds ratio for any dichotomous variable was 1.5 , for the variable asking whether the student's parent expected them to continue beyond GCSEs.

\section{Appendix 3: Alternative Model Specifications}

See Table 10.

Table 10 ATT results for models when re-run with alternate kernel specifications

\begin{tabular}{|c|c|c|c|c|c|}
\hline \multirow[t]{2}{*}{ Outcome } & \multirow[t]{2}{*}{ Subsample } & \multicolumn{4}{|l|}{ Kernel type } \\
\hline & & Epan. & Uniform & Normal & Biweight \\
\hline \multirow[t]{2}{*}{ A-levels } & All & $.077(.015)$ & $.084(.014)$ & $.106(.014)$ & $.074(.014)$ \\
\hline & Parent/caregiver holds & & & & \\
\hline A-levels & No qualifications & $.115(.039)$ & $.110(.037)$ & $.130(.037)$ & $.101(.037)$ \\
\hline A-levels & 10th grade qualification & $.128(.031)$ & $.133(.030)$ & $.158(.030)$ & $.119(.030)$ \\
\hline A-levels & 12th grade qualification & $.042(.036)$ & $.060(.034)$ & $.082(.034)$ & $.050(.034)$ \\
\hline \multirow[t]{2}{*}{ A-levels } & University degree & $.055(.021)$ & $.056(.021)$ & $.073(.021)$ & $.051(.021)$ \\
\hline & Academic achievement & & & & \\
\hline A-levels & Lower & $.084(.033)$ & $.075(.030)$ & $.084(.030)$ & $.070(.030)$ \\
\hline A-levels & Middle & $.117(.026)$ & $.132(.025)$ & $.145(.025)$ & $.125(.025)$ \\
\hline A-levels & Upper & $.034(.015)$ & $.036(.015)$ & $.041(.015)$ & $.033(.015)$ \\
\hline \multirow[t]{2}{*}{ University } & All & $.041(.016)$ & $.048(.015)$ & $.072(.015)$ & $.036(.015)$ \\
\hline & Parent/caregiver holds & & & & \\
\hline University & No qualifications & $.103(.039)$ & $.093(.036)$ & $.116(.036)$ & $.082(.036)$ \\
\hline University & 10th grade qualification & $.073(.031)$ & $.086(.029)$ & $.108(.029)$ & $.071(.029)$ \\
\hline University & 12th grade qualification & $.031(.037)$ & $.043(.035)$ & $.065(.034)$ & $.033(.034)$ \\
\hline \multirow[t]{2}{*}{ University } & University degree & $.001(.025)$ & $.007(.024)$ & $.025(.024)$ & $-.002(.024)$ \\
\hline & Academic achievement & & & & \\
\hline University & Lower & $.046(.028)$ & $.034(.026)$ & $.043(.026)$ & $.027(.026)$ \\
\hline University & Middle & $.104(.026)$ & $.121(.024)$ & $.132(.024)$ & $.114(.024)$ \\
\hline University & Upper & $-.016(.020)$ & $-.015(.020)$ & $-.009(.020)$ & $-.019(.020)$ \\
\hline
\end{tabular}




\section{References}

Adnett, N., \& Tlupova, D. (2007). Variable tuition fees and widening participation: Issues and some early evidence. Paper presented at the British Educational Research Association Annual Conference, London, UK. Retrieved from http://www.staffordshire.ac.uk/schools/business/iepr/docs/workingpaper37. pdf.

Alderman, H., Behrman, J. R., Kohler, H. P., Maluccio, J. A., \& Watkins, S. (2001). Attrition in longitudinal household survey data: Some tests for three developing-country samples. Demographic Research, 5, 79-124.

Allison, P. D. (2002). Missing data. Thousand Oaks, CA: Sage.

Anders, J. (2012a). Using the longitudinal study of young people in England for research into higher education access (No. 12-13), Department of Quantitative Social Science-Institute of Education, University of London.

Anders, J. (2012b). The link between household income, university applications and university attendance. Fiscal Studies, 33(2), 185-210.

Anders, J., \& Micklewright, J. (2013). Teenagers' expectations of applying to university: How do they change? (No. 13-13), Department of Quantitative Social Science, Institute of Education, University of London, London, UK.

Archer, L., \& Hutchings, M. (2000). 'Bettering yourself'? Discourses of risk, cost and benefit in ethnically diverse, young working-class non-participants' constructions of higher education. British Journal of Sociology of Education, 21(4), 555-574.

Archer, L., Hutchings, M., \& Ross, A. (2003). Higher education and social class: Issues of exclusion and inclusion. London: Routledge Falmer.

Archer, L., \& Leathwood, C. (2003). Identities, inequalities and higher education. In L. Archer, M. Hutchings, \& A. Ross (Eds.), Higher education and social class: Issues of exclusion and inclusion (pp. 171-191). London: Routledge Falmer.

Archer, L., Pratt, S. D., \& Phillips, D. (2001). Working-class men's constructions of masculinity and negotiations of (non) participation in higher education. Gender and Education, 13(4), 431-449.

Baker, L., \& Wigfield, A. (1999). Dimensions of children's motivation for reading and their relations to reading activity and reading achievement. Reading Research Quarterly, 34, 452-477.

Ball, S. J. (2003). Class strategies and the education market: The middle classes and social advantage. London: Routledge Falmer.

Ball, S. J. (2008). The education debate: Policy and politics in the twenty-first century. Bristol: The Policy Press.

Ball, S. J., Davies, J., David, M., \& Reay, D. (2002a). 'Classification' and 'judgement': Social class and the 'cognitive structures' of choice of higher education. British Journal of Sociology of Education, 23(1), 51-72.

Ball, S. J., Reay, D., \& David, M. (2002b). 'Ethnic choosing': Minority ethnic students, social class and higher education choice. Race, Ethnicity and Education, 5(4), 333-357.

Becker, S. O., \& Caliendo, M. (2007). Mhbounds-sensitivity analysis for average treatment effects. IZA Discussion Paper No. 2542. Available at SSRN: https://ssrn.com/abstract=958699.

Berzin, S. C. (2010). Educational aspirations among low-income youths: Examining multiple conceptual models. Children \& Schools, 32(2), 112-124.

Blanden, J., \& Machin, S. (2004). Educational inequality and the expansion of UK higher education. Scottish Journal of Political Economy, 51(2), 230-249.

Blundell, R., Dearden, L., \& Sianesi, B. (2005). Evaluating the effect of education on earnings: Models, methods and results from the National Child Development Survey. Journal of the Royal Statistical Society: Series A (Statistics in Society), 168(3), 473-512.

Boaler, J. (1997). Setting, social class and the survival of the quickest. British Educational Research Journal., 23(5), 575-595.

Bourdieu, P. (1986). Distinction: A social critique of the judgement of taste. London: Routledge \& Kegan Paul.

Bourdieu, P. (1990). The logic of practice. Cambridge: Polity Press.

Bourdieu, P. (1998). The state nobility: Elite schools in the field of power. Stanford, CA: Stanford University Press.

Bourdieu, P. (2005). The social structures of the economy. Cambridge: Polity Press.

Bourdieu, P., \& Passeron, J. C. (1977). Reproduction in education, society, and culture. Beverly Hills, CA: Sage.

Bourdieu, P., \& Passeron, J. C. (1979). The inheritors: French students and their relation to culture. Chicago: University of Chicago Press. 
Bourdieu, P., \& Passeron, J. C. (1990). Reproduction in education, society and culture. London: Sage.

Bourdieu, P., \& Wacquant, L. (1992). An invitation to reflexive sociology. Chicago, IL: University of Chicago Press.

Burke, P. J. (2010). Masculinity, subjectivity and neoliberalism in men's accounts of migration and accessing higher education. Gender and Education, 23(2), 169-184.

Caliendo, M., \& Kopeinig, S. (2008). Some practical guidance for the implementation of propensity score matching. Journal of Economic Surveys, 22(1), 31-72.

Chowdry, H., Crawford, C., Dearden, L., Goodman, A., \& Vignoles, A. (2008). Widening participation in higher education: Analysis using linked administrative data. London: Institute for Fiscal Studies.

Chowdry, H., Crawford, C., Dearden, L., Goodman, A., \& Vignoles, A. (2013). Widening participation in higher education: Analysis using linked administrative data. Journal of the Royal Statistical Society: Series A (Statistics in Society), 176(2), 431-457.

Chowdry, H., Dearden, L., Hin, W., \& Lloyd, B. (2012). Fees and student support under the new higher education funding regime: What are different universities doing? IFS Briefing Note BN 134. London, UK: Institute for Fiscal Studies.

Christie, H., \& Munro, M. (2003). The Logic of Loans: Students' perceptions of the costs and benefits of the student loan. British Journal of Sociology of Education, 24(5), 621-636.

Cochrane, M. (2007). Spoilt for choice? Pupil perceptions of the options process at Year 9. Paper presented at the British Educational Research Association Annual Conference, London, 5-8 September. Retrieved from http://www.leeds.ac.uk/educol/documents/165852.htm.

Cochrane, M. (2011). Children's university aspirations and the effects of cultural and social capital. In J. Adams, M. Cochrane, \& L. Dunne (Eds.), Applying theory to educational research: An introductory approach with case studies (pp. 95-107). Hoboken: Wiley.

Cohen, J., Cohen, P., West, S. G., \& Aiken, L. S. (2003). Applied multiple regression/correlation analysis for the behavioral sciences. Mahwah, NJ: L. Erlbaum Associates.

Crossley, N. (2001). The phenomenological habitus and its construction. Theory and Society, 30(1), 81-120.

Department for Education and National Centre for Social Research. (2012). Longitudinal study of young people in England: Waves one to seven, 2004-2010 (12th ed.), UK Data Archive, Colchester, UK. SN: 5545.

Dolan, L. J. (1983). Validity analyses for the School Attitude Measures at three grade levels. Educational and Psychological Measurement, 43, 295-303.

Eisenhart, M. A. (2009). Generalizing from educational research. In K. Ercikan \& W. M. Roth (Eds.), Generalizing from educational research: Beyond qualitative and quantitative polarization (pp. 51-66). New York, NY: Routledge.

Foster, P., Gomm, R., \& Hammersley, M. (1996). Constructing educational inequality. London: Falmer Press.

Franklin, M. (1995). The effects of differential college environments on academic learning and student perceptions of cognitive development. Research in Higher Education, 36(2), 127-153.

Frolich, M. (2004). Finite-sample properties of propensity-score matching and weighting estimators. Review of Economics and Statistics, 86(1), 77-90.

Galindo-Rueda, F., Marcenaro-Gutierrez, O., \& Vignoles, A. (2004). The widening socio-economic gap in UK higher education. National Institute Economic Review, 190(1), 75-88.

Gasper, J., DeLuca, S., \& Estacion, A. (2012). Switching schools: Revisiting the relationship between school mobility and high school dropout. American Educational Research Journal, 49(3), 487-519.

Gibbons, S., \& Vignoles, A. (2012). Geography, choice and participation in higher education in England. Regional science and urban economics, 42(1), 98-113.

Giddens, A. (1991). Modernity and self-identity: Self and society in the late modern age. Stanford, CA: Stanford University Press.

Glennerster, H. (2001). United Kingdom education, 1997-2001. London: London School of Economics and Political Science.

Goldstein, H. (2009). Handling attrition and non-response in longitudinal data. Longitudinal and Life Course Studies, 1(1), 63-72.

Gorard, S., \& Selwyn, N. (1999). Switching on the learnig society?-questioning the role of technology in widening participation in lifelong learning. Journal of Education Policy, 14(5), 523-534.

Gottfried, A. E., \& Gottfried, A. W. (1996). A longitudinal study of academic intrinsic motivation in intellectually gifted children: Childhood through early adolescence. Gifted Child Quarterly, 40, $179-183$.

Gunn, S. (2005). Translating Bourdieu: Cultural capital and the English middle class in historical perspective. The British journal of sociology, 56(1), 49-64. 
Guo, S., \& Fraser, M. W. (2010). Propensity score analysis: Statistical methods and applications. Thousand Oaks, CA: Sage.

Harrison, N. (2013). Modelling the demand for higher education by local authority area in England using academic, economic and social data. British Educational Research Journal, 39(5), 793-816.

Heckman, J. J., Ichimura, H., \& Todd, P. (1998). Matching as an econometric evaluation estimator. The Review of Economic Studies, 65(2), 261-294.

Hollingworth, S., \& Archer, L. (2009). Urban schools as urban places: School reputation, children's identities and engagement with education in London. Urban Studies, 47(3), 584-603.

Jackson, M. (2011). Social background and educational transitions in England. Paper presented at the annual meeting of the American Sociological Association Annual Meeting, Caesar's Palace, Las Vegas, NV.

Jackson, M., \& Jonsson, J. O. (2013). Why does inequality of educational opportunity vary across countries? Primary and secondary effects in comparative context. In M. Jackson (Ed.), Determined to succeed? Performance versus choice in educational attainment (pp. 306-338). Stanford, CA: Stanford University Press.

Jones, M. P. (1996). Indicator and stratification methods for missing explanatory variables in multiple linear regression. Journal of the American Statistical Association, 91(433), 222-230.

Lareau, A. (1997). Social class differences in family-school relationships: The importance of cultural capital. In A. H. Halsey, H. Lauder, P. Brown, \& A. S. Wells (Eds.), Education: Culture, economy, society (pp. 713-717). Oxford: Oxford University Press.

Lee, L. (2008). The impact of young people's internet use on class boundaries and life trajectories. Sociology, 42(1), 137-153.

Little, R. J. (1992). Regression with missing X's: A review. Journal of the American Statistical Association, 87(420), 1227-1237.

Machin, S., \& Vignoles, A. (2004). Educational inequality: The widening socio-economic gap. Fiscal Studies, 25(2), 107-128.

Mantel, N., \& Haenszel, W. (1959). Statistical aspects of the analysis of data from retrospective studies of disease. Journal of the National Cancer Institute, 22, 719-748.

Marcenaro-Gutierrez, O., Galindo-Rueda, F., \& Vignoles, A. (2007). Who actually goes to university? The Economics of Education and Training, 32(2), 333-357.

Marsh, H. W., Craven, R. G., Hinkley, J. W., \& Debus, R. L. (2003). Evaluation of the Big-Two-Factor Theory of academic motivation orientations: An evaluation of jingle-jangle fallacies. Multivariate Behavioral Research, 38(2), 189-224.

McHarg, J., Mattick, K., \& Knight, L. V. (2007). Why people apply to medical school: Implications for widening participation activities. Medical Education, 41(8), 815-821.

Midgley, C., Maehr, M. L., Hruda, L. Z., Anderman, E., Anderman, L., Freeman, K. E., et al. (2000). Manual for the patterns of adaptive learning scales (PALS). Ann Arbor: University of Michigan.

Mills, C. (2008). Reproduction and transformation of inequalities in schooling: The transformative potential of the theoretical constructs of Bourdieu. British Journal of Sociology of Education, 29(1), 79-89.

Molenberghs, G., \& Fitzmaurice, G. (2008). Incomplete data: Introduction and over-view. In G. Fitzmaurice, M. Davidian, G. Verbeke, \& G. Molenberghs (Eds.), Longitudinal data analysis (pp. 395-408). Boca Raton, FL: CRC Press.

Moogan, Y. J. (2011). An analysis of school pupils'(with low social economic status) perceptions of university, regarding programmes of study. Educational Studies, 37(1), 1-14.

Nash, R. (2005). Cognitive habitus and collective intelligence: Concepts for the explanation of inequality of educational opportunity. Journal of Education Policy, 20(1), 3-21.

Oliver, C., \& Kettley, N. (2010). Gatekeepers or facilitators: The influence of teacher habitus on students' applications to elite universities. British Journal of Sociology of Education, 31(6), 737-753.

Ovenden, K. (2000). The politics of protest. Socialist Review, 242. Retrieved from http://pubs. socialistreviewindex.org.uk/sr242/contents.htm.

Pennell, H., \& West, A. (2005). The impact of increased fees on participation in higher education in England. Higher Education Quarterly, 59(2), 127-137.

Piesse, A., \& Kalton, G. (2009). A strategy for handling missing data in the Longitudinal Study of Young People in England (LSYPE). DCSF-RW086. Department for Children, Schools and Families, London, UK.

Pintrich, P. R., Smith, D. A., García, T., \& McKeachie, W. J. (1993). Reliability and predictive validity of the Motivated Strategies for Learning Questionnaire (MSLQ). Educational and Psychological Measurement, 53(3), 801-813.

Preston, J. (2003). White trash vocationalism? Formations of class and race in an Essex further education college. Widening participation and lifelong learning, 5(2), 6-17. 
Pugsley, L. (1998). Throwing your brains at it: Higher education, markets and choice. International Studies in Sociology of Education, 8(1), 71-92.

Reay, D. (1995). 'They employ cleaners to do that': Habitus in the primary classroom. British Journal of Sociology of Education, 16(3), 353-371.

Reay, D. (1998). 'Always knowing' and "never being sure": Familial and institutional habituses and higher education choice. Journal of Education Policy, 13(4), 519-529.

Reay, D. (2004). "It's all becoming a habitus": Beyond the habitual use of Pierre Bourdieu's concept of habitus in educational research. British Journal of Sociology of Education, 25(4), 431-444.

Reay, D. (2005). Beyond consciousness? The psychic landscape of social class. Sociology, 39(5), 911-928.

Reay, D. (2006). The zombie stalking English schools: Social class and educational inequality. British journal of educational studies, 54(3), 288-307.

Reay, D. (2013). Social mobility, a panacea for austere times: Tales of emperors, frogs, and tadpoles. British Journal of Sociology of Education, 34(5-6), 660-677.

Reay, D., Crozier, G., \& Clayton, J. (2009). 'Strangers in paradise'? Working-class students in elite universities. Sociology, 43(6), 1103-1121.

Reay, D., David, M. E., \& Ball, S. J. (2001). Making a difference?: Institutional habituses and higher education choice. Sociological Research Online, 5(4), U126-U142.

Redmond, P. (2006). Outcasts on the inside: Graduates, employability and widening participation. Tertiary Education and Management, 12(2), 119-135.

Reynolds, C. L., \& DesJardins, S. L. (2009). The use of matching methods in higher education research: Answering whether attendance at a 2-year institution results in differences in educational attainment. Higher Education: Handbook of Theory and Research, 24, 47-97.

Rose, D., Pevalin, D. J., \& O'Reilly, K. (2005). The national statistics socio-economic classification: Origins, development and use. Basingstoke, UK: Palgrave Macmillan.

Rosenbaum, P. R., \& Rubin, D. B. (1983). Assessing sensitivity to an unobserved binary covariate in an observational study with binary outcome. Journal of the Royal Statistical Society: Series B, 45(2), 212-218.

Rubin, D. B. (1997). Estimating causal effects from large data sets using propensity scores. Annals of Internal Medicine, 2(127), 757-763.

Savage, M. (2000). Class analysis and social transformation. Buckingham: Open University Press.

Sayer, A. (2005). Class, moral worth and recognition. Sociology, 39(5), 947-963.

Shanghai Ranking Consultancy. (2014). Academic ranking of world universities 2014. Shanghai Jiao Tong University, Shangai, China. Retrieved from http://www.shanghairanking.com/ARWU2014.html.

Steedman, C. (1988). The mother made conscious: The historical development of primary school pedagogy. In M. Woodhead \& A. McGrath (Eds.), Family, school \& society (pp. 82-95). London: The Open University.

Stevenson, H., \& Wood, P. (2014). Markets, managerialism and teachers' work: The invisible hand of high stakes testing in England. International Education Journal: Comparative Perspectives, 12(2), 42-61.

Thomas, L., Bland, D., \& Duckworth, V. (2012). Teachers as advocates for widening participation. Widening Participation and Lifelong Learning, 14(2), 40-58.

Thrupp, M. (1999). Schools making a difference: Let's be realistic! School mix, school effectiveness and the social limits of reform. Buckingham: Open University Press.

Times Higher Education. (2015). World university rankings 2014-2015. Retrieved from https://www. timeshighereducation.co.uk/world-university-rankings/2015/world-ranking/\#/.

U.S. News and World Report. (2015). Best global universities rankings. Retrieved from http://www.usnews. com/education/best-global-universities/rankings.

United Kingdom Government. (2012). Education (recognised bodies) (England) order 2010. Retrieved from http://www.legislation.gov.uk/uksi/2010/2618/contents/made.

Vallerand, R. J., Pelletier, L. G., Blais, M. R., Briere, N. M., Senecal, C., \& Vallieres, E. F. (1992). The academic motivation scale: A measure of intrinsic, extrinsic, and amotivation in education. Educational and Psychological Measurement, 52(4), 1003-1017.

Vignoles, A. (2013). Widening participation and social mobility. In C. Callendar \& P. Scott (Eds.), Browne and beyond: Modernizing English higher education (pp. 112-129). London: Institute of Education Press. 